\title{
Thaw Penetration in Frozen Ground Subjected to Hydronic Heating
}

\author{
Svein-Erik Sveen ${ }^{1}$, Hung Thanh Nguyen ${ }^{2}$, and Bjørn Reidar Sørensen ${ }^{3}$
}

\begin{abstract}
To facilitate excavation and foundation work in seasonally freezing or permafrost regions, the frozen soil must be thawed, either by natural (solar) thawing, or by artificial thawing where an auxiliary heat source is utilized to accelerate the process. In this paper, the process of rapid thawing of frozen ground subject to hydronic heating is studied. In particular, the performance characteristics of the method is evaluated through full-scale thawing experiments performed on three types of homogenous, initially frozen soils. The results from two separate experiments, carried out during the winter of 2011 and 2012, were compared. The corresponding soil temperature increase, phase change and variation in water content for each type of soil were monitored. The results from both winter seasons show similar trends, with comparable and considerable higher thaw rates for gravelly sand $(\sim 3.5$ days $/ \mathrm{m})$ and silty sand ( $\sim$ days $/ \mathrm{m})$ compared with crushed gravel ( $\sim 11.5$ days $/ \mathrm{m})$. Furthermore, thaw rates compiled from thermistor strings in tubes embedded in the ground are overestimated compared with similar temperature readings based on thermocouples in direct contact with the soil.
\end{abstract}

Author keywords: Artificial thawing; Hydronic heating; Performance characteristics; Ground temperature.

\section{Introduction}

In regions experiencing seasonal frost or permafrost, the techniques used for thawing of frozen soil have evolved with a growing demand for higher efficiency and the need for extending the construction season. The winter has traditionally been a low season for enterprises reliant on frost-free ground conditions to carry out their work. In these regions, overall project costs are up to 10 times higher attributable to the need for importing much of the materials and labor, and adapting construction practices to the more severe working conditions (Freitag and McFadden 1997). Contractors, landscape architects, municipalities, and utility companies struggling with production standstills

1 Assistant professor, UiT-Norwegian Arctic University, Faculty of Engineering Science and Technology, Institute of Building, Energy and Material Technology, P.O. Box 385, 8505 Narvik, Norway (corresponding author). E-mail: svein-erik.sveen@uit.no

2 Associate professor, UiT-Norwegian Arctic University, Faculty of Engineering Science and Technology, Institute of Building, Energy and Material Technology, P.O. Box 385, 8505 Narvik, Norway. E-mail: hung.thanh.nguyen@uit.no

${ }_{3}$ Professor, UiT-Norwegian Arctic University, Faculty of Engineering Science and Technology, Institute of Building, Energy and Material Technology, P.O. Box 385, 8505 Narvik, Norway. E-mail: bjorn.r.sorensen@uit.no 
and staff layoffs during the cold season will therefore benefit greatly from cost-effective methods that can facilitate year-round operation.

Over the years, several methods have been tried to thaw frozen ground. One of the first on record was the direct use of fires to thaw the gold-rich alluvial deposits of sands and gravels, during the gold rush to Alaska and northern Canada in the late 1800s (Beistline 1963). With the mechanization of the mine workings in the early 1900s, other methods such as cold water and steam thawing came into favor, as mentioned by Esch (2004) in his introduction. More recent efforts include coal fires, propane heaters, electric heaters (Oswell and Graham 1987), microwave (Lindroth et al. 1995) and infrared heating (Hermansson and Guthrie 2006), none of which seem to have seen further development or extensive use after the initial trials.

In comparison, since the introduction to the U.S. and Canadian markets two decades ago (Stewart 1996), artificial ground thawing based on hydronic heat has become increasingly more widespread. Further innovations and improvements by European manufacturers have made the method prevalent also in Europe. In this context, the term artificial refers to the use of water-borne (hydronic) heat to accelerate the thawing process (Jumikis 1979).

To facilitate full-scale experiments on frozen soils, an outdoors frost in ground laboratory (FiG-lab) was established in 2011. The present study is the first to benefit from access to these lab facilities by performing full-scale thawing experiments on various types of homogenous soils. Specifically, the purpose of the investigation was to evaluate the performance characteristics of the hydronic method used for thawing of frozen ground. To achieve this, an external heat source operating by this principle was used to provide the heat necessary for the thawing process. The resulting soil temperature increase, phase change and variation in water content for each soil type were monitored during the process.

This paper discusses principles of hydronic heating and the results from the experimental work, including basic information about the FiG-lab and instrumentation. A full description of the lab-facilities and supplementary information is given in a separate paper (Sveen and Soerensen 2013).

\section{Hydronic Heating}

Central heating is a well-known concept for providing heat in residential buildings originating from the ancient Roman civilization (Bansal and Shail 1999). Wealthy citizens kept their homes warm by passing hot combustion gases from a furnace (hypocaust) through cavity walls and floors. As opposed to space heating, the heat generation occurred in the cellar by a furnace burning wood. Modern central heating systems are based on the same principle, with a central heating unit where the heat is distributed throughout the building typically by forced air through ductwork or water circulating through pipes. The hydronic thawing system operates in the same manner, 

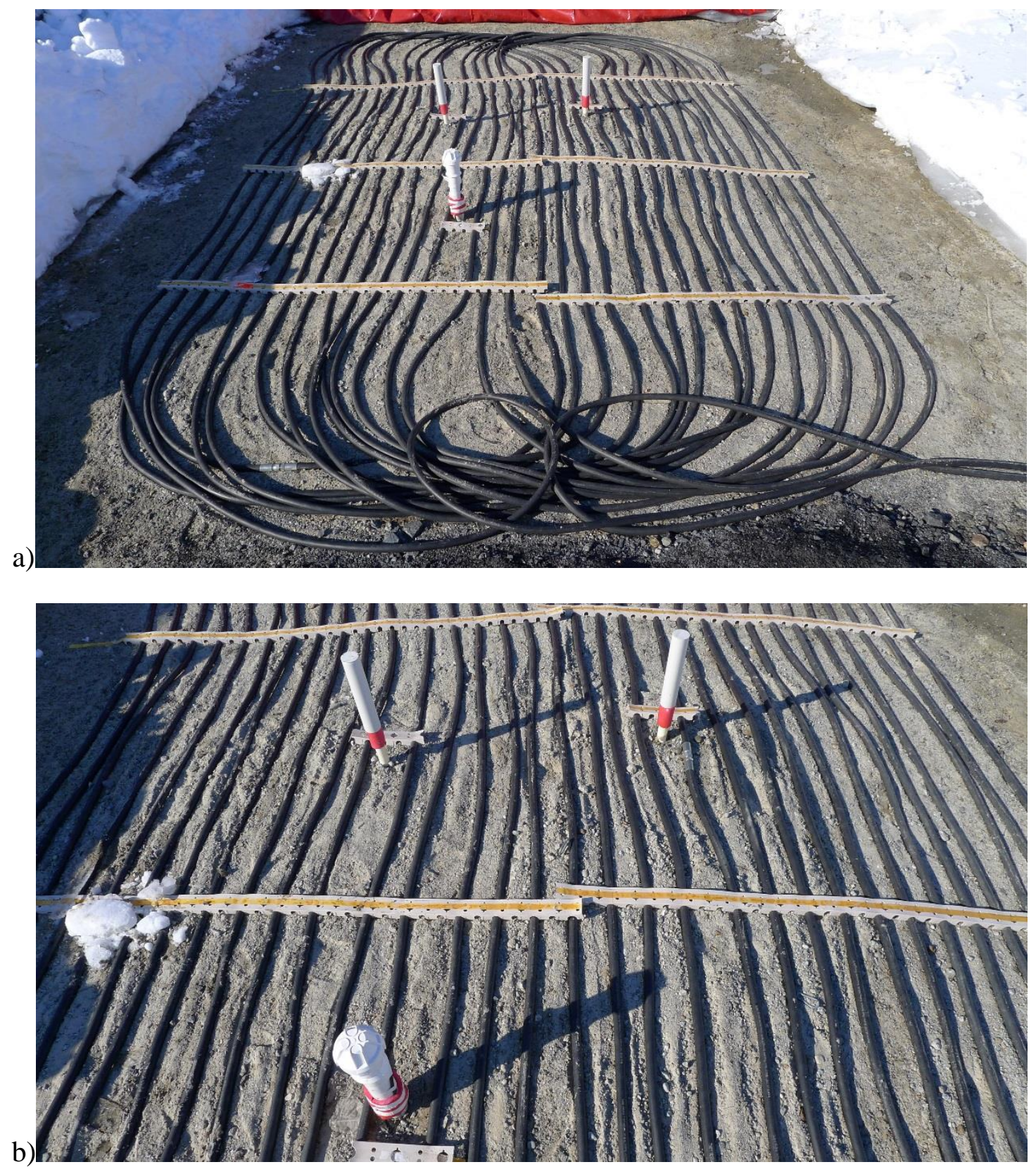

Fig. 1. (a) Overview; (b) close-up of hot-water pipes laid out on gravelly sand, April 19th, 2012 (images by Svein-Erik Sveen)

using a mixture of water and glycol as the heating medium, although it is somewhat modified and made portable to accommodate field use as shown in Fig. 1.

\section{Defrosting System}

The main components and principle of operation are shown in Fig. 2. An oil burner is used to heat the water-glycol mixture contained in the boiler. A pump ensures circulation of the hot fluid through flexible rubber hoses or pipes connected to a 


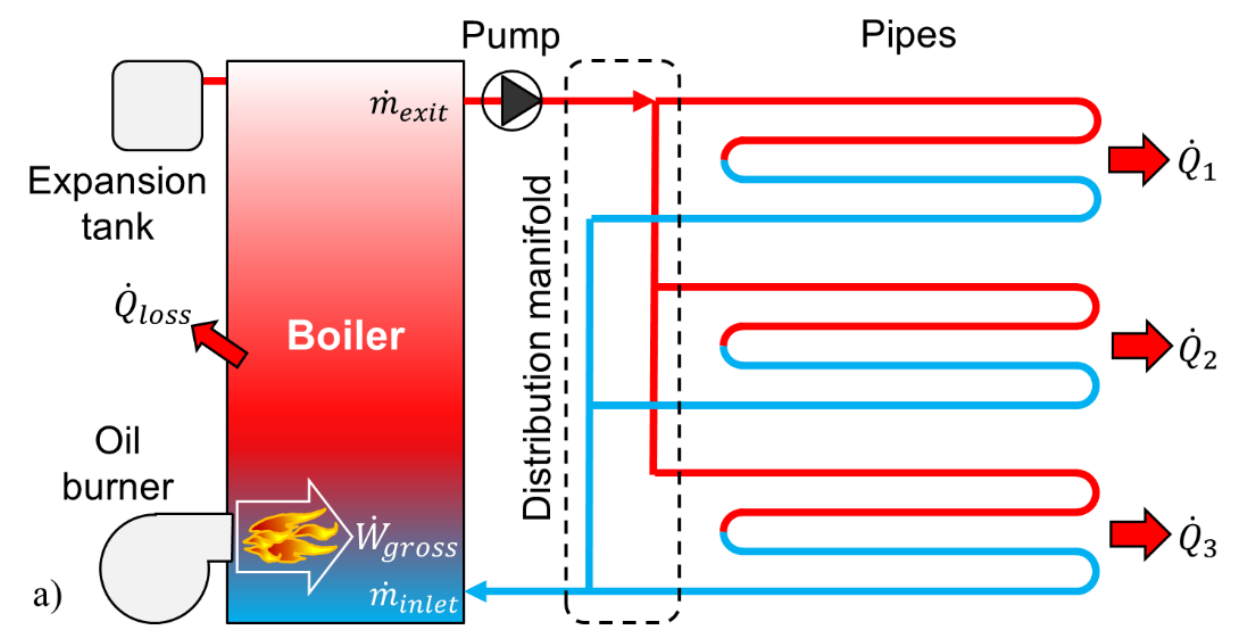

b)

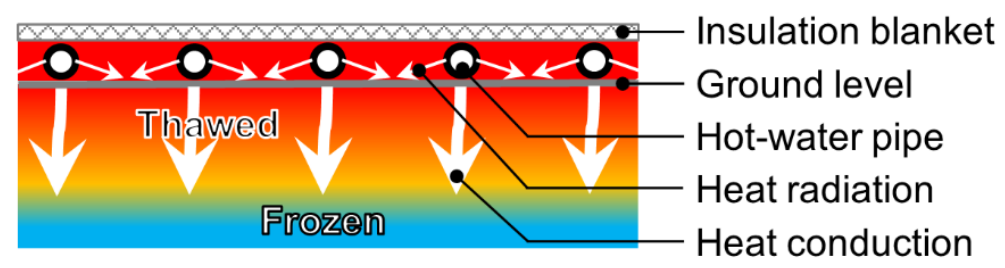

Fig. 2. (a) Main components; (b) principle of operation of a hydronic defrosting system during artificial thawing of frozen ground (side view)

distribution manifold mounted on the boiler. The manifold divides the flow evenly between up to three pipes, allowing for single, dual or triple pipe operation. When the pipes are laid out on the frozen ground surface, they are covered with combined vapor barrier and insulation blankets to reduce the heat loss during thawing. The horizontal spacing between the pipes varies from 10 to $40 \mathrm{~cm}$ in regions with seasonal frost, and $0-5 \mathrm{~cm}$ when placed on permafrost.

According to the manufacturer, the system used in this study has a 50-L boiler heated by a $103 \mathrm{~kW}$ oil burner. It has three flexible distribution pipes available, each $210 \mathrm{~m}$ in length, outer diameter of $24 \mathrm{~mm}$ and holding approximately $42 \mathrm{~L}$ of fluid. The distribution manifold regulates the number of active pipes during thawing operations.

\section{Heat Load}

The boiler temperature is set manually up to $100^{\circ} \mathrm{C}$ by a thermostat. During a short startup period, the burner will run continuously (i.e., at full capacity) until the desired set temperature is reached. At the start, the temperature difference between the fluid supplied by the boiler (constant) and the fluid returning (rising) is at its maximum. As the temperature of the frozen ground surface gradually increases and instigates the thawing process, the temperature difference will become lower. 


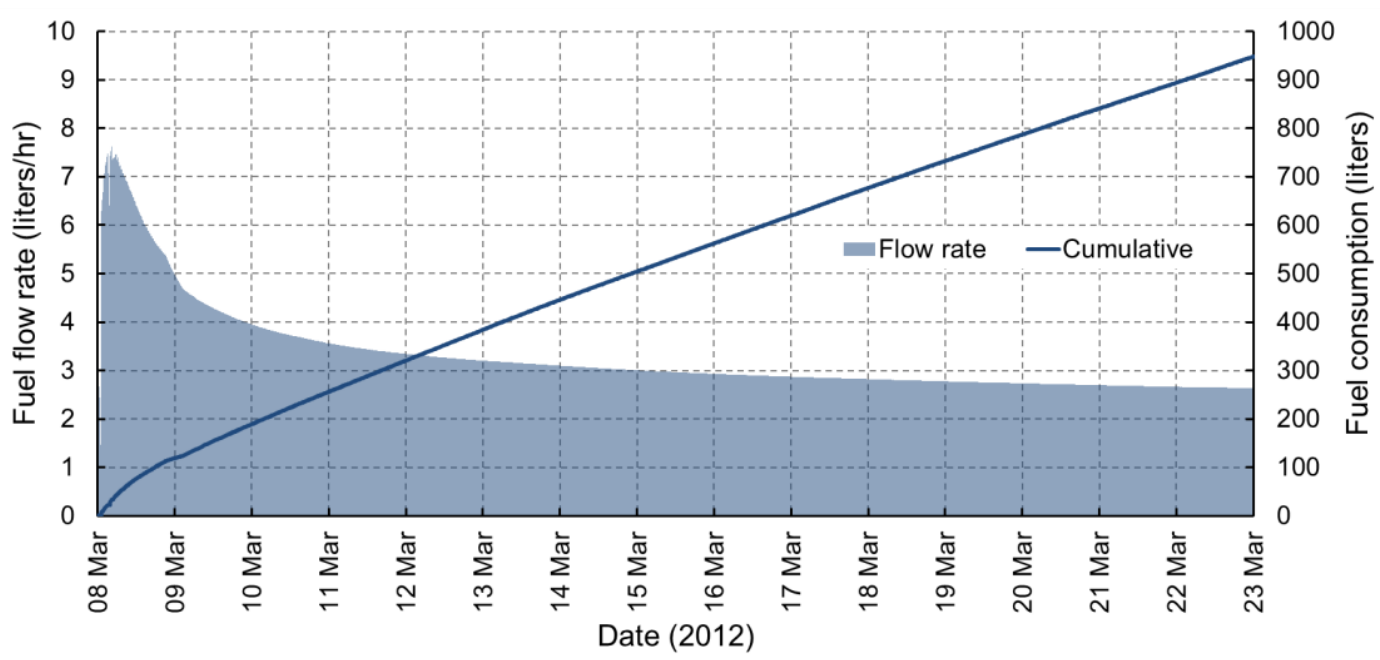

Fig. 3. Typical fuel flow rate and cumulative fuel consumption of the hydronic defrosting system during artificial thawing, example from March 2012

Increasing return temperatures indicates that the burner does not have to run continuously to maintain the set temperature of the boiler. As the ground temperatures becomes higher, the intermittence factor increases. In practice, this indicates lower demand for fuel as the thawing progresses, as illustrated by the fuel flow rate shown in Fig. 3.

The fuel consumption is proportional to the total heat output from the defrosting system. According to Fig. 3 the fuel flow rate decreases with time, which indicates that the system delivers a transient heat load, i.e., not constant during thawing operations.

\section{Energy Balance}

Referring to Figs. 2(a) and 3, the maximum or actual heat output of the system $\left(\dot{Q}_{1}+\right.$ $\left.\dot{Q}_{2}+\dot{Q}_{3}\right)$ is considerably lower than the stated gross effect $\left(\dot{W}_{\text {gross }}\right)$ of the oil burner. The actual heat transfer rate to the fluid in the boiler is expressed as the product of the fuel flow rate and net calorific value of the fuel used, multiplied by the theoretical maximum burner efficiency (TSI 2004), which is typically between 80 and 95\%. An efficiency of $100 \%$ is not achievable owing to the inherent flue gas loss and because of radiation and convection losses from the boiler surface. In this case, given a constant fuel flow rate of $8.30 \mathrm{~L} / \mathrm{h}$, a net calorific value of $9.96 \mathrm{kWh} / \mathrm{L}$ of the diesel and a burner efficiency of $94 \%$, the maximum heat transfer rate $(\dot{W})$ becomes $77.7 \mathrm{~kW}$. As the thawing progresses and the burner starts running intermittent, the rate will start decreasing, thus gradually lowering the heat output available for thawing.

The boiler can be considered a control volume $(c v)$ where the mass flow in and out is both constant and equal. During a steady-flow process the total energy content of the $c v$ 
is constant $\left(E_{c v}=\right.$ constant), i.e., the change in the total energy content of the $c v$ is zero $\left(\Delta E_{c v}=0\right)$. Thus, the amount of energy entering the $c v$ in all forms (heat, work, mass transfer) must be equal to the amount of energy leaving it. Based on the conservation of energy principle, the water-glycol mixture will experience an increase in its total energy as it flows through the boiler, which is equal to the energy supplied by the burner minus the heat losses. Assuming a constant mass flow in and out of the $c v$, including the kinetic and potential energy of the circulating fluid, the energy balance of a system with multiple exits $(e)$ and inlets $(i)$ can be expressed per unit time (rate) as follows (Cengel 2002)

$$
\dot{Q}-\dot{W}=\sum \dot{m}\left(h_{e}+\frac{v_{e}^{2}}{2}+g z_{e}\right)-\sum \dot{m}\left(h_{i}+\frac{v_{i}^{2}}{2}+g z_{i}\right)
$$

where $\dot{m}=$ mass flow rate $(\mathrm{kg} / \mathrm{s}) ; h=$ enthalpy $(\mathrm{J} / \mathrm{kg})$ and $v=$ velocity $(\mathrm{m} / \mathrm{s})$ of the fluid leaving and entering the control volume; $g=$ standard acceleration of gravity $(9.81$ $\left.\mathrm{m} / \mathrm{s}^{2}\right)$; and $z=$ height $(\mathrm{m})$ of the exit and the inlet, respectively. In the case of the defrosting system used, it is a closed system with no changes in fluid velocity and insignificant difference in elevation between the exit and inlet. Changes in kinetic and potential energies are therefore negligible. By substituting the enthalpies by the corresponding exit and inlet temperatures $(\mathrm{K})$ and using the specific heat $\left(c_{p}\right.$ in $\mathrm{J} / \mathrm{kgK}$ ) of the fluid, Eq. (1) can be rewritten as follows:

$$
\dot{Q}-\dot{W}=\sum \dot{m} c_{p}\left(T_{\text {exit }}-T_{\text {inlet }}\right)
$$

Applied to the defrosting system shown in Fig. 2(a), where the distribution manifold only has a single exit and inlet connected to the boiler independent of the number of pipes being used during thawing operations, Eq. (2) reduces to the following:

$$
\dot{Q}-\dot{W}=\dot{m} c_{p}\left(T_{\text {exit }}-T_{\text {inlet }}\right)(W)
$$

From a practical point of view, the left-hand term of Eq. (3) represents the net heat transfer to the fluid in the boiler in $W$, where the flue gas loss of the oil burner and heat losses from the boiler surface are accounted for. The right-hand term represents the heat output, i.e., from the heated fluid circulating in up to three pipes connected to the distribution manifold. In the case of single pipe operation, the available heat is distributed through that pipe alone, thus the exit and inlet temperatures of the manifold connected to the boiler are equal to those of the pipe. In the case of dual or triple pipe operation, the exit temperatures of the manifold and the pipes will still be equal, but the inlet temperature of the manifold will represent an average of the inlet temperatures of the pipes actually in use.

\section{Methodology}

This study is based on full-scale experiments carried out during the winters of 2011 and 2012 at the frost in ground laboratory (FiG-lab, N68 $26^{\prime} 55^{\prime \prime}$, E1 $\left.17^{\circ} 31^{\prime} 16^{\prime \prime}\right)$, located 


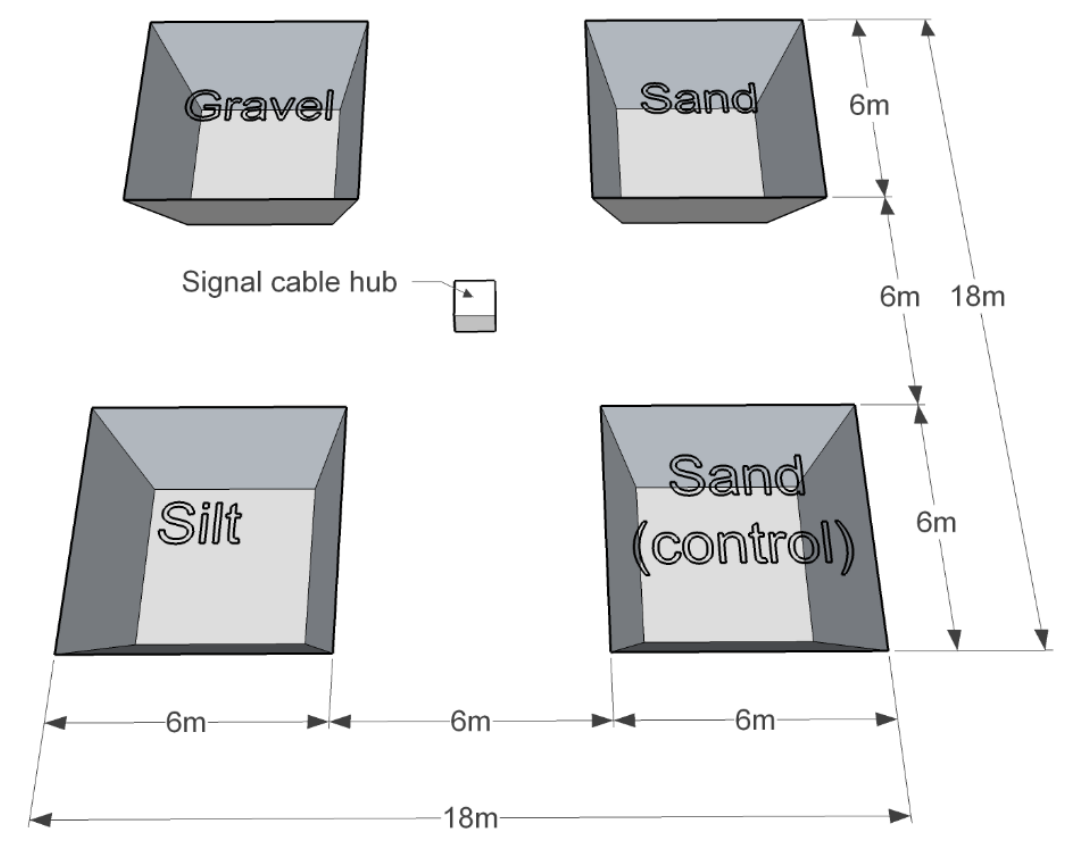

Fig. 4. Overview of the frost in ground laboratory soil-bin arrangement

approximately $6 \mathrm{~km}$ east-northeast of Narvik, Norway. The preparations made, procedures followed and defrosting system used were the same for both experiments. A separate paper (Sveen and Soerensen 2013) contains detailed information about the laboratory. For clarity, key points are reiterated in the following sections.

\section{Performance Test Arrangement}

To evaluate the performance characteristics of the hydronic thawing method, three types of soils were thawed simultaneously, using the previously described hydronic defrosting system. A flat area at an elevation of approximately $140 \mathrm{~m}$ above sea level was prepared at the FiG-lab, replacing the uppermost $3 \mathrm{~m}$ of the existing soil with moraine gravel. An $18 \times 18$ m field was established within the area, with four $6 \times 6 \mathrm{~m}$ soil-bins placed in a quadratic pattern as shown in Fig. 4.

The existing soil of each bin was exchanged with homogenous soil samples; gravelly sand, silty sand and 8-22 mm uniform, crushed gravel. The additional sand (control) bin was included to ensure the integrity of the bins actually being thawed during the experiments. There is no physical barrier separating the soil samples in the sand and silty sand bins from the adjacent soil, except for a thin, permeable membrane in gravel preventing infiltration of adjacent soil. A hub for the signal cabling leading from the bins are located at the center of the field, from where the cables lead to a cabin sheltering the monitoring systems. The layout of a typical soil bin is shown in Fig. 5. 


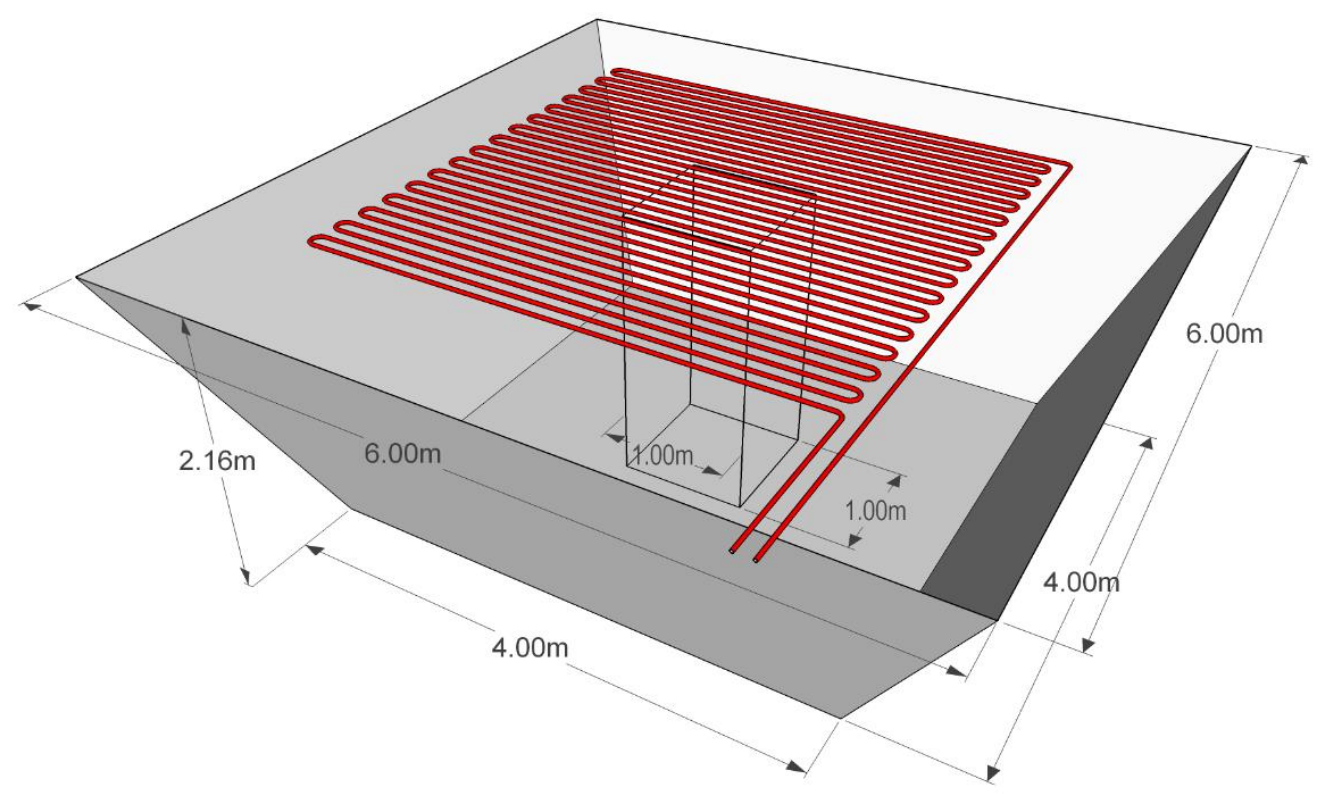

Fig. 5. Overview of a soil-bin with flexible hot-water pipes laid out on the ground surface, covering an area of approximately $4.5 \times 4.5 \mathrm{~m}$; the four bins have identical dimensions and instrumentation

Soil temperature monitoring was initiated when the FiG-lab was operative in March 2011 to track seasonal variations of frost and thaw penetration. During the 2-week thawing experiments in April 2011 and March 2012, soil temperature and moisture content in all four bins were recorded every h using piers of thermocouples, thermistors, resistance blocks and volumetric moisture sensors. In addition, the fuel consumption, pipe flow rates and temperatures of the hydronic defrosting system were monitored at similar intervals. The vertical alignment of the various sensors was ensured by strapping them to a custom-made frame placed at the center of each bin. The vertical spacing between the thermocouples is $0.1 \mathrm{~m}$, starting at the ground surface level and ending at $1.8 \mathrm{~m}$ depth. The remaining groups of sensors end at the same depth, but are placed at $0.2 \mathrm{~m}$ intervals, starting from $0.1 \mathrm{~m}$ below the ground surface, which indicates they are aligned with every second thermocouple. The sensor frame extends $2.16 \mathrm{~m}$ vertically and covers a 1 x $1 \mathrm{~m}$ horizontal area as indicated in Fig. 5.

During both winter seasons, ambient air conditions and precipitation were gathered from a nearby meteorological station maintained by the Norwegian Meteorological Institute. Approximately three months after the first experiment in April 2011, soil samples was collected from each bin for determination of grain-size distribution, porosity, initial moisture content and dry density. Similar sampling was performed after the second experiment in March 2012. 
Table 1. Soil Classification, Bulk Density and Volumetric Water Content

\begin{tabular}{|c|c|c|c|c|c|}
\hline \multirow{2}{*}{$\begin{array}{l}\text { Soil } \\
\text { bin }\end{array}$} & \multicolumn{2}{|r|}{ Unified soil classification } & \multirow{2}{*}{$\begin{array}{l}\text { Bulk density } \\
\qquad\left(\mathrm{kg} / \mathrm{m}^{3}\right)\end{array}$} & \multicolumn{2}{|c|}{$\begin{array}{c}\text { Volumetric water } \\
\text { content }(\%)\end{array}$} \\
\hline & Group & Description & & 2012 & 2011 \\
\hline $\mathrm{A}^{\mathrm{a}}$ & & Gravelly sand (33.4\% gravel, & & $6.7^{\mathrm{b}}$ & $29.8^{c}$ \\
\hline $\mathrm{B}$ & SP & $62.9 \%$ sand, $3.7 \%$ fines) & 1,190 & 12.1 & 12.1 \\
\hline $\mathrm{C}$ & SP-SM & $\begin{array}{c}\text { Sand-silt mixture }(16.3 \% \text { gravel, } \\
76.6 \% \text { sand, } 7.1 \% \text { fines })\end{array}$ & 1,727 & 12.8 & 13.2 \\
\hline $\mathrm{D}$ & GP & $\begin{array}{l}\text { Poorly graded gravel ( } 98.9 \% \\
\text { gravel, } 0.7 \% \text { sand, } 0.4 \% \text { fines) }\end{array}$ & 1,446 & 4.0 & 4.1 \\
\hline
\end{tabular}

Note: Volumetric water content are average values based on readings from the topmost three soil moisture sensors $(0.1,0.3$ and $0.5 \mathrm{~m}) 48 \mathrm{~h}$ into each thawing experiment (10th of March 2012 and 11th of April 2011, respectively).

${ }^{a}$ Control bin, monitored, but not part of the thawing experiment.

${ }^{\mathrm{b}}$ Average reading in frozen soil.

${ }^{\mathrm{c}}$ Average reading in naturally thawed soil.

\section{Results}

In the following sections, details about the soils tested, weather conditions and soil temperature records from the experiments performed in 2012 and 2011 are presented. Because the 2011 dataset is incomplete, it is presented after the one in 2012 instead of chronologically. Additional results and analysis based on the records of soil moisture and phase change variations will be presented in a subsequent paper.

\section{Soils Tested}

The materials used in the performance testing are characterized as coarse grained soils (i.e., more than half of the material finer than $75 \mathrm{~mm}$ and larger than $0.075 \mathrm{~mm}$ ) and grouped in accordance with the Unified Soil Classification System (Andersland and Ladanyi 2004) as shown in Table 1. The listed bulk (dry) densities are the average of three soil samples per bin, taken from separate trenches during the summers of 2011 and 2012, respectively. The listed volumetric water content represents the average of the uppermost $0.5 \mathrm{~m}$ layer, based on soil moisture readings made two days into each experiment, i.e., before the lower layer was thawed and the excess water was drained out. Initial values for water and ice content do not exist, as frozen soil cores were not collected prior to thawing resulting from lack of access to suitable sampling equipment.

The grain-size distribution curves for the soils used are shown in Fig. 6, together with the effective diameter $\left(D_{10}\right)$, the coefficient of uniformity $\left(C_{u}\right)$, and the coefficient of curvature $\left(C_{c}\right)$ for sand. 


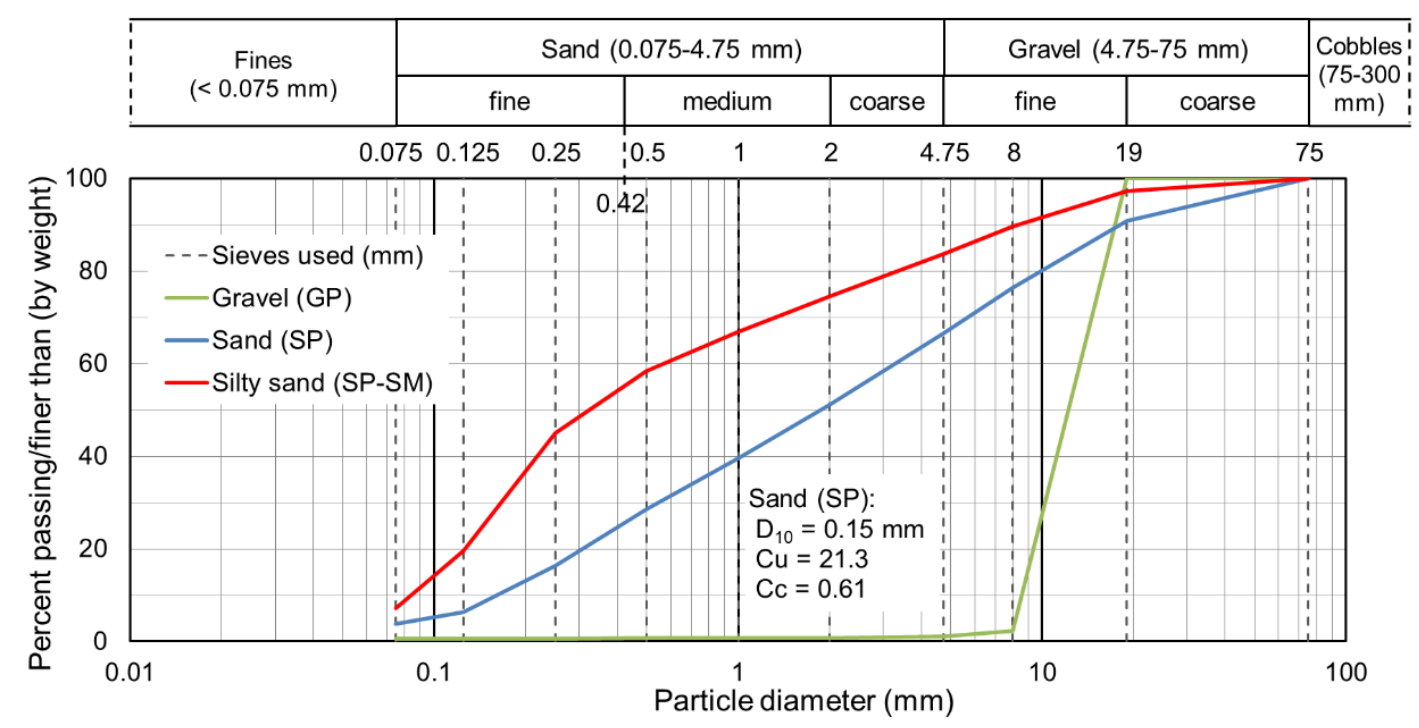

Fig. 6. Grain-size distribution curves (group classification in parenthesis) for the types of soils used in the experiments; the effective diameter $\left(D_{10}\right)$, coefficient of uniformity $\left(C_{u}\right)$ and coefficient of curvature $\left(C_{c}\right)$ apply only to sand (SP)

\section{Weather Conditions}

Fig. 7 shows records of daily mean, high, and low air temperatures, and precipitation one week prior to and during the experiments. They are collected from an official weather station maintained by the Norwegian Meteorological Institute (NMI), located at Straumsnes approximately $5.5 \mathrm{~km}$ east of the FiG-lab, $200 \mathrm{~m}$ above sea level.

Referring to NMI's 1961-1990 climate normal (30-year average), mean annual air temperature and frost index for a normal year in Narvik is $3.8^{\circ} \mathrm{C}$ and $9,000 \mathrm{~h}^{\circ} \mathrm{C}$ (degree $\mathrm{h}$ ), respectively. The cold season for the region is 5 months, from the beginning of November to the end of March, i.e., where monthly mean air temperatures are below $0^{\circ} \mathrm{C}$.

According to public records from NMI covering January-February 2012, the weather conditions were characterized by slightly higher air temperatures and less precipitation compared with the previous year. There was almost no precipitation, and consequently moderate snow cover $(<25 \mathrm{~cm})$ was present until February 10th. The snow cover stayed the same until the last week of February, during which it increased to approximately 60 $\mathrm{cm}$. At that time, it was removed as a part of the preparations for the fieldwork.

Mean air temperature for the period $1 \mathrm{st}-23 \mathrm{rd}$ of March 2012 was $-0.7^{\circ} \mathrm{C}$, referring to Fig. 7 (a), and $0.1^{\circ} \mathrm{C}$ during the period of artificial thawing, 8th-23rd of March. Daily average precipitation during the experiment was $3.8 \mathrm{~mm}$, primarily as snow. Based on the thermocouple records for silty sand, the frost depth was 1.4-1.5 m. For gravelly sand, the frost depth was between 1.5 and $1.8 \mathrm{~m}$, and for uniform gravel more than 1.8 $\mathrm{m}$. 


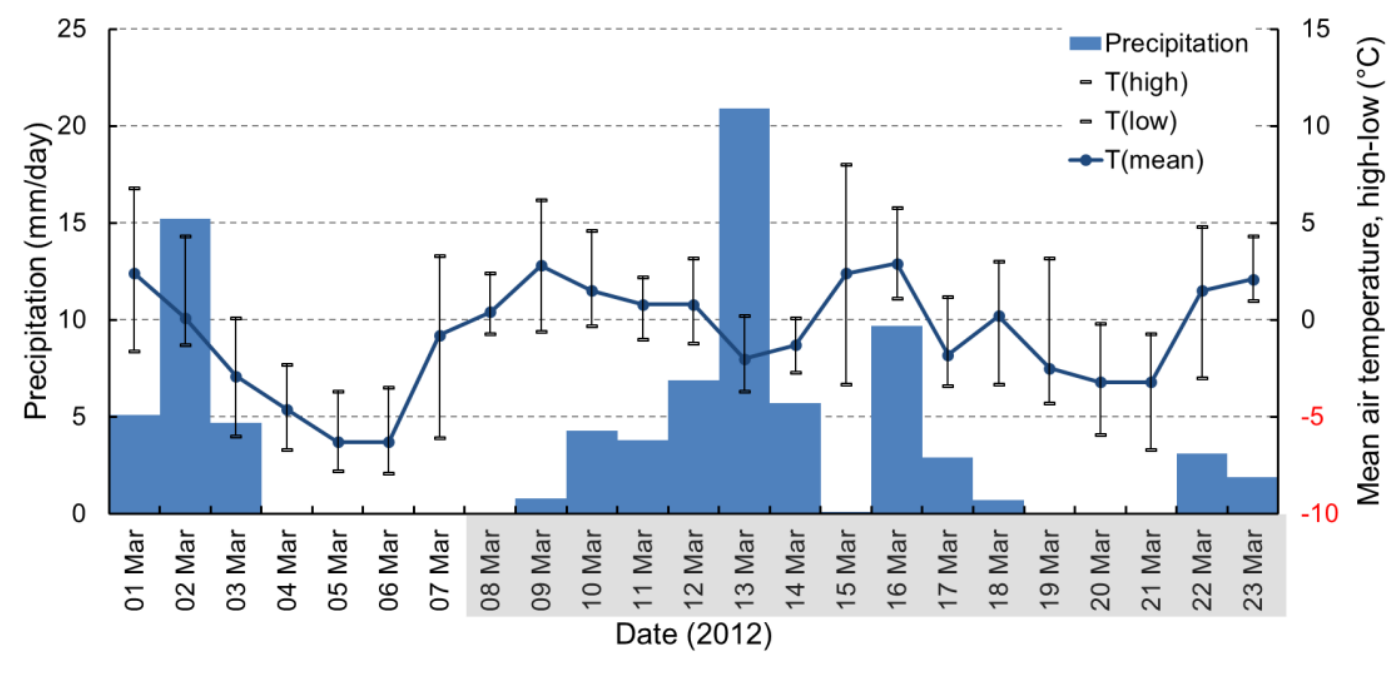

a)

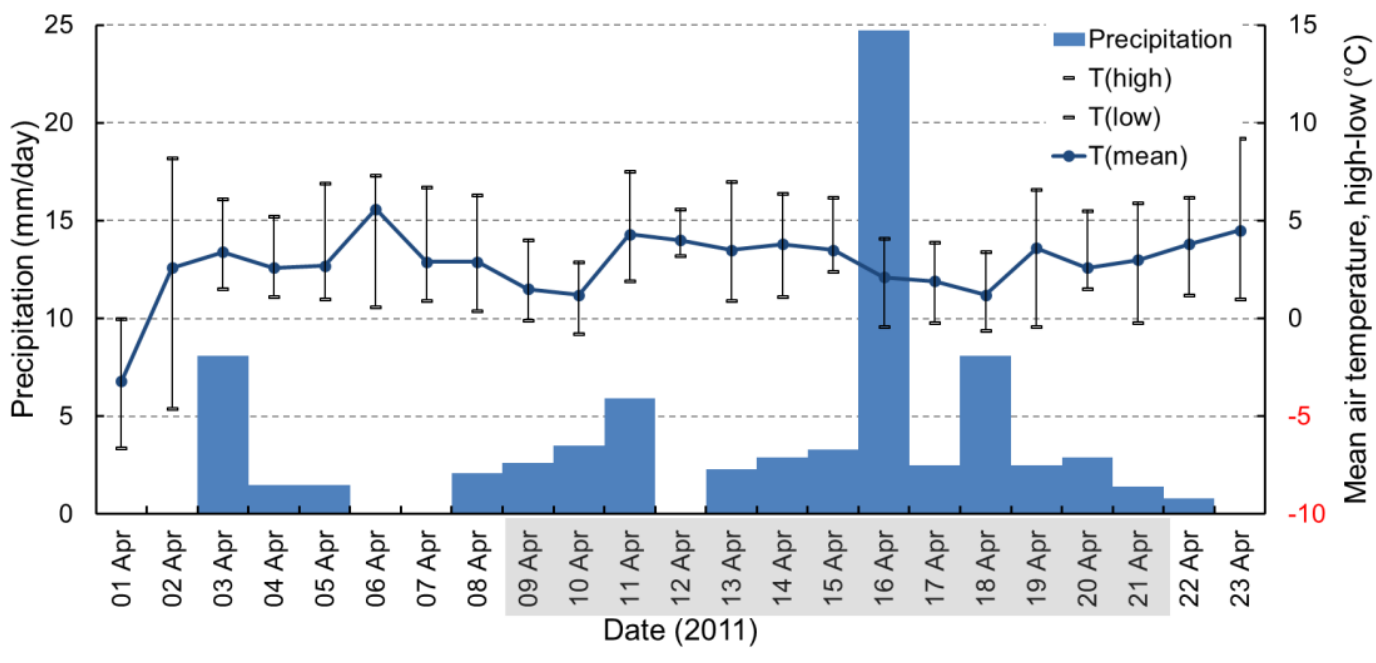

Fig. 7. Daily mean air temperatures and precipitation one week prior to and during the experiments (shaded) carried out in (a) March 2012; (b) April 2011

Similarly, the NMI records covering January-March 2011, show slightly lower air temperatures and more precipitation in general compared with the same period the following year. There was no snow cover until January 27th, increasing to approximately $70 \mathrm{~cm}$ in mid-February and varying between 50 and $80 \mathrm{~cm}$ until the beginning of April. It was removed approximately one week prior to the experiments. As opposed to 2012, there were several warm spells in the month leading up to the fieldwork, combined with precipitation in the form of rain or sleet.

Based on the thermocouple records for silty sand from 2011, the ground was frozen at 1.1-1.2 m depth. For gravelly sand and uniform gravel, the frost depth was approximately $1.5 \mathrm{~m}$. Mean air temperature for the period $1 \mathrm{st}-21 \mathrm{st}$ of April was $2.7^{\circ} \mathrm{C}$, referring to Fig. 7(b). During the experiments 9th-21st of April, the mean temperature was $2.8^{\circ} \mathrm{C}$ and average precipitation was $4.8 \mathrm{~mm}$ per day, primarily as rain and sleet. 


\section{Soil Temperature Profiles}

Fig. 8 shows soil temperature records from $1400 \mathrm{hrs}$ March 8th to $1400 \mathrm{hrs}$ March 21st 2012 for three types of homogenous soils being thawed simultaneously. The records are based on hourly thermocouple readings. To avoid clutter, only readings for every second sensor are shown, i.e., eight sensors at $0.2 \mathrm{~m}$ intervals covering the range from 0.1 to $1.5 \mathrm{~m}$ depth, in addition to the ones at the ground surface level $(0 \mathrm{~m})$ and at the bottom $(1.8 \mathrm{~m})$ of the bin.

In general, soil temperatures are higher and the increase steeper near the hot-water pipes at the surface. Temperature slopes decline with time and are dampened with increasing depth. Thermal responses in sand [Fig. 8(a)] occurs slightly earlier on the time axis compared with silty sand [Fig. 8(b)], with gravel [Fig. 8(c)] responding the slowest and experiencing the lowest temperatures. The time delay between the responses at one depth compared with the next is nonlinear, i.e., increasing with depth.

Forty-eight $\mathrm{h}$ into the experiment, the thaw has penetrated to approximately $0.65 \mathrm{~m}$ in sand, $0.52 \mathrm{~m}$ in silty sand and $0.40 \mathrm{~m}$ in gravel. The time needed for the thaw to penetrate to $1.1 \mathrm{~m}$ depth is $96 \mathrm{~h}$ (4 days) in sand, $108 \mathrm{~h}$ (4.5 days) in silty sand and 336 $\mathrm{h}$ (14 days) in gravel.

Similarly, Fig. 9 shows soil temperature records from $1000 \mathrm{hrs}$ April 10th to $1800 \mathrm{hrs}$ April $21^{\text {st }}, 2011$ for similar soils, based on the same type of sensors and methodology as in 2012. Data are missing for the first part of the experiment attributable to problems with the data acquisition system in the beginning, resulting in a loss of thermocouple records for the initial $17 \mathrm{~h}$ of the experiment.

Referring to Fig. 9 in general, apart from silty sand, the temperature profiles are similar to those in 2012, although slightly lower and the thermal responses appearing somewhat later on the time axis. After $48 \mathrm{~h}$, the thaw has penetrated to $0.65 \mathrm{~m}$ depth in sand and $0.43 \mathrm{~m}$ in gravel. The time needed for the thaw to penetrate to $1.1 \mathrm{~m}$ depth is $106 \mathrm{~h}$ (4.4 days) in sand and $95 \mathrm{~h}$ ( 4 days) in silty sand. In gravel, there was no thermal response at $1.1 \mathrm{~m}$ depth at the time the experiment ended.

For silty sand [Fig. 9(b)], the early temperature profiles at approximately $0.5-0.9 \mathrm{~m}$ depth are reversed, suggesting that natural thawing had started prior to the experiment. Beside some resemblance noticeable at $0.7 \mathrm{~m}$ depth, the same is not apparent in sand [Fig. 9(a)]. From examining the temperature and soil moisture records for the control bin (Fig. 4), it is clear that natural thawing had already started before the experiment was up and running in 2011. Diurnal air temperature variations are replicated by the soil temperatures down to approximately $0.4 \mathrm{~m}$ in the control bin, but with an increasing time lag and lower amplitudes with depth. 


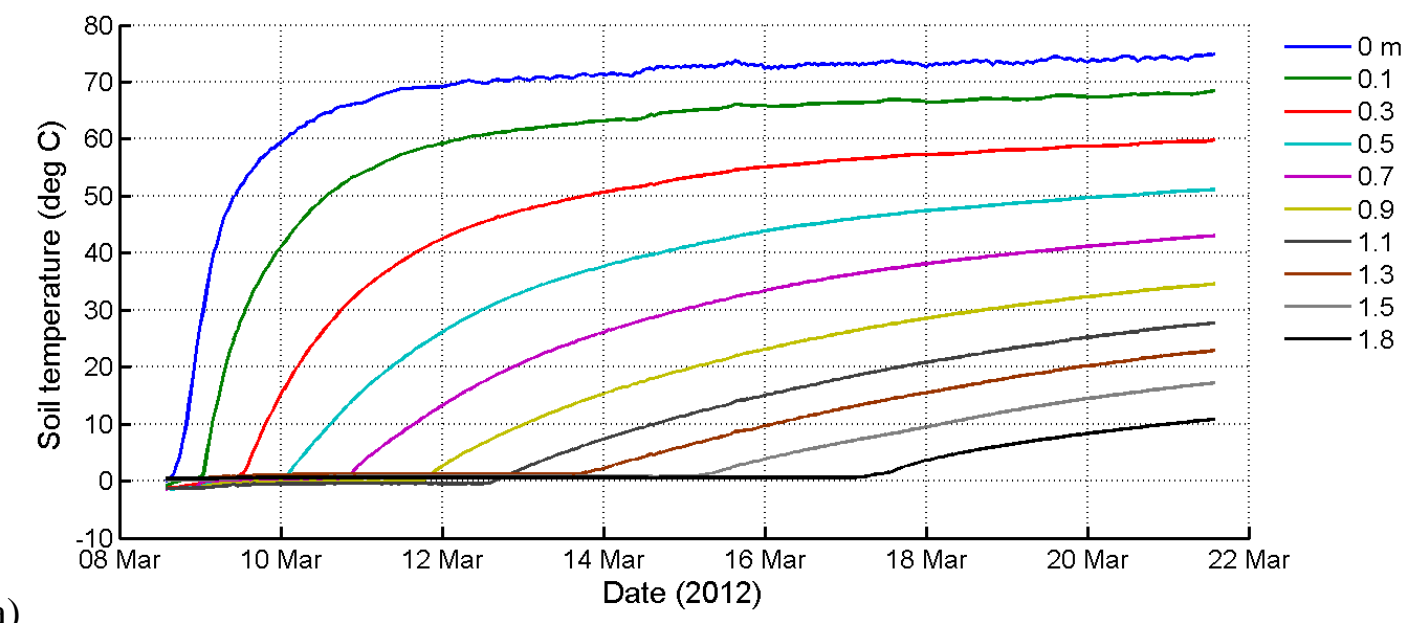

a)

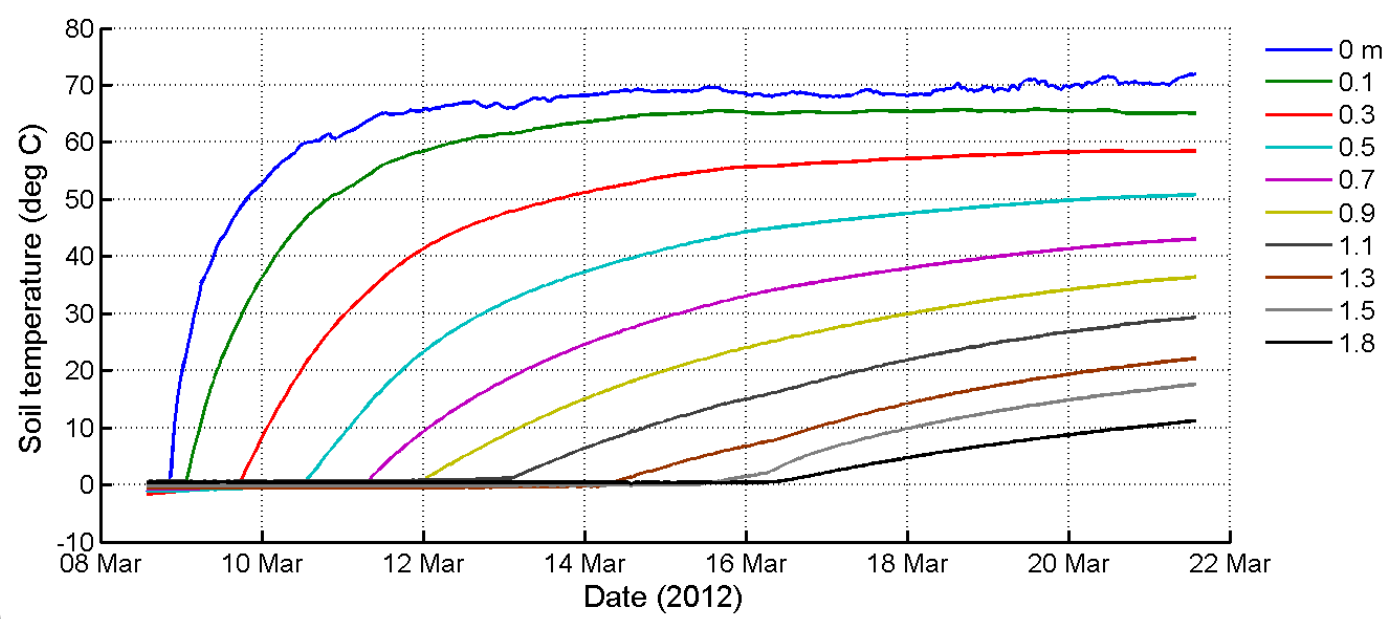

b)

Date (2012)

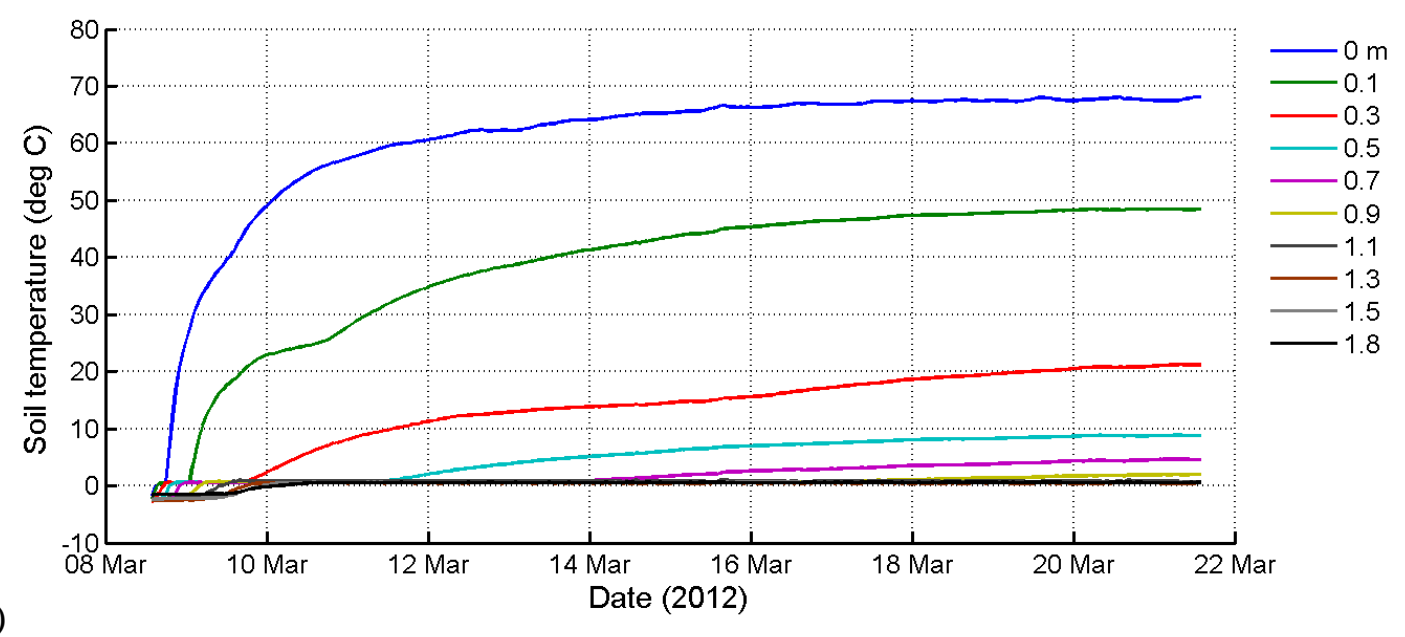

Fig. 8. Soil temperatures in homogenous; (a) gravelly sand; (b) silty sand; (c) 8-22 mm uniform, crushed gravel, March 2012 


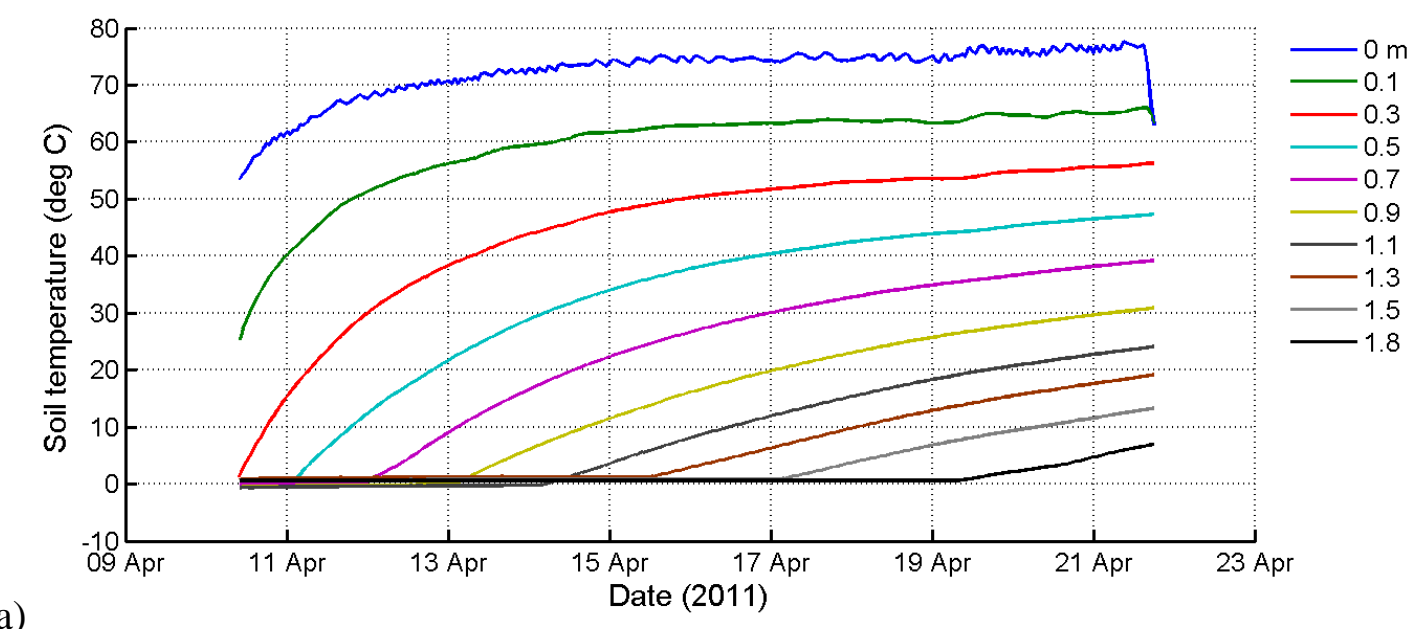

a)

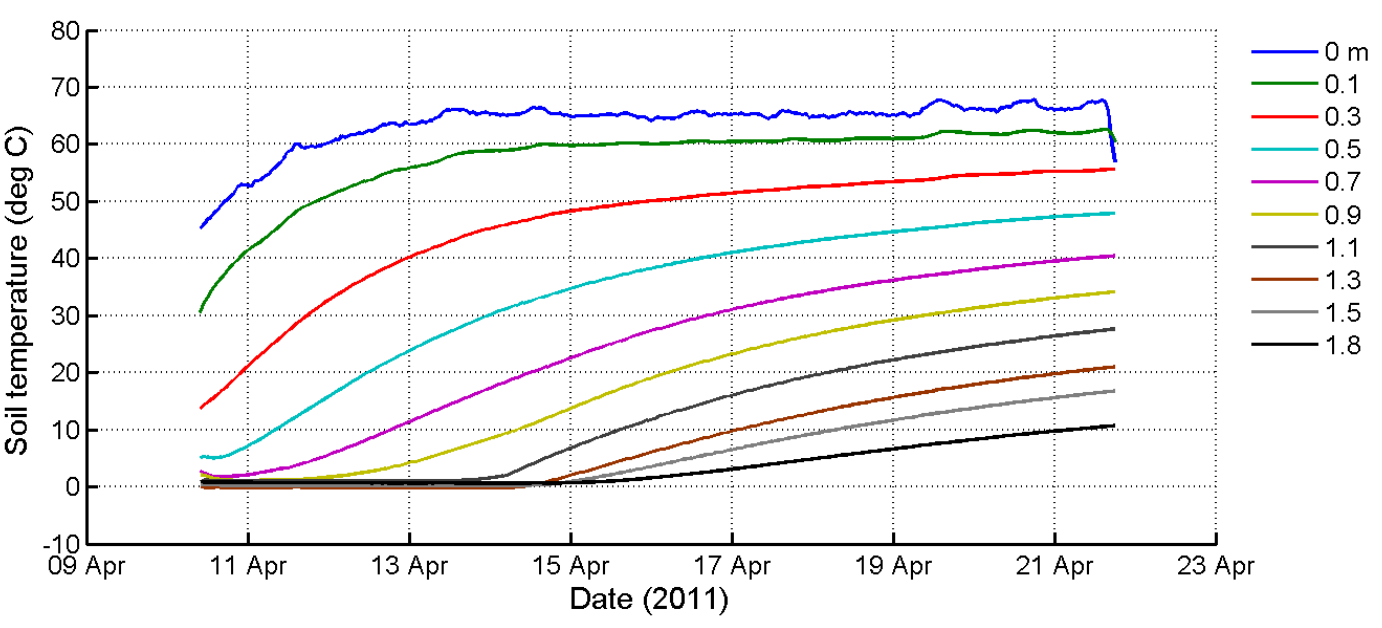

b)

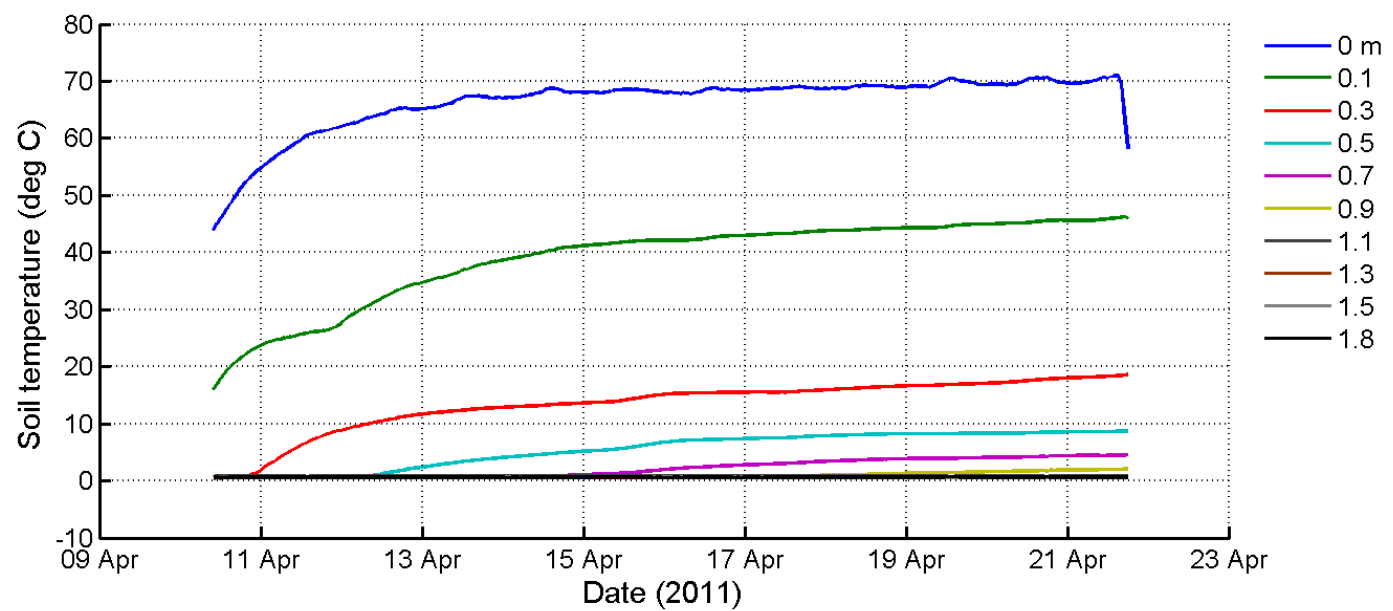

c)

Fig. 9. Soil temperatures in homogenous; (a) gravelly sand; (b) silty sand; (c) 8-22 $\mathrm{mm}$ uniform, crushed gravel, April 2011 


\section{Discussion and Conclusion}

In the following sections, the soils used and the temperature datasets obtained during the performance testing of the hydronic method in 2012 and 2011 are discussed. Together with thaw rate comparisons based on the complete thermocouple and thermistor string records from 2012, the resulting thaw rates from both winter seasons are presented. In addition, the performance rate of thawing by hydronic heat is compared with similar artificial thawing methods.

\section{Soil Types}

The soils employed in the experiments are coarse-grained soils typically used when building foundations, pipe trenches and road bases. In regions with seasonal or permafrost, soils such as silty sand would not see much use because of its high proportion of fines and consequently its susceptibility to frost. Nevertheless, it is included to complement the other two types of soil with regard to grain-size distribution and to ensure conformity with the soils used in an initial experiment carried out in 2007 (Sveen and Soerensen 2010). Considering only two full-scale thawing experiments in the present study, that is of importance because it provides an additional dataset to compare with.

The soil samples in the bins are referred to as being homogenous. In context, that indicates being of the same type from the ground surface and downwards, even though the grain-size distribution ranges from smaller than $0.075 \mathrm{~mm}$ (fines) in silty sand up to $75 \mathrm{~mm}$ in gravelly sand. From Table 1, and when observing the similarity of the temperature trends in Figs. 8(a and b), it appears that the soil composition of gravelly and silty sand could have been more diverse. Although the grain-size distribution curves suggests an adequate difference between the two, an even bigger proportion of fines in silty sand would increase its water susceptibility and thus the time needed to thaw it from frozen state (Andersland and Ladanyi 2004).

Because the soil bins are exposed to the elements, seasonal and annual variations of soil moisture, ice content and frost depths are expected. Even if these parameters were nearly the same from one winter to the next, they are of interest as the initial conditions decide the baseline for the experiments. Furthermore, actually measuring the thermal conductivity as the soil changes from frozen to thawed state would provide additional information and a broader basis for analyzing the results or for performing numerical simulations of the hydronic thawing process, although the latter is outside the scope of this study. Lack of access to suitable sampling equipment prevented the collection of such data. As a substitute, Table 1 contains average values based on readings from the moisture sensors in the upper $0.5 \mathrm{~m}$ two days into each of the thawing experiments.

Although not actually defining the baseline for the experiments, these moisture levels provide at least an indication of the relative differences in water content between the 
soils. The readings for gravelly sand and silty sand should be representative as the thaw had penetrated well beyond $0.5 \mathrm{~m}$ at the time. For gravel, the water content readings are not entirely accurate because the thaw only had penetrated to approximately $0.40-0.43$ $m$ depth at the same time.

\section{Soil Temperatures}

The temperature profiles shown in Figs. 8 and 9 give an impression of the heat transfer occurring in three types of initially frozen soils subject to hydronic heating, based on two separate experiments. More specifically, transient, one-dimensional heat and mass transfer in porous media is an over simplification because the soils are three-phase materials consisting of solids, water, and gas (air). When frost is present, the soil could be considered a four-phase material because of parts of the water being frozen (Jumikis 1979). Given the extreme heat load the soils are exposed to during a short time interval, the resulting thermal responses are what might be expected.

During the initial, transient phase, the temperatures near the heat source rise sharply until they approach a level dependent primarily on the supply temperature and the combined heat capacity of the different constituencies of the soil. The increase then becomes gradually smaller until the temperatures reach a phase resembling steady state. The same temperature trends are found deeper into the ground for all soils investigated, although rising at a lesser rate as the depth increases.

Compared with natural thawing, typically lasting for 2-3 months in this region, artificial thawing is completed in a matter of days in similar types of soil and with normal frost depths. Because the heat is distributed within a small area of frozen ground, the underlying soil thaws rapidly and stays oversaturated until the zero isotherm has penetrated the frozen layer and the excess water is allowed to drain out. Thus, in soils with lower porosity such as silty or gravelly sand, water will greatly influence the thawing process compared with porous soils such as uniform gravel.

With the exception of silty sand [Fig. 9(b)], the temperature trends and levels in the experiment from 2011 are similar to those from 2012. Because the former was carried out one month later in the year and outside the normal cold season, natural thawing is likely to have had an influence during the time leading up to the experiment. Because 2011 was the first fieldwork season after establishing the FiG-lab, there are no soil temperature records prior to the experiment to support the assumption regarding the occurrence of previous thaw-freeze cycles. Examining meteorological records from NMI for a plausible explanation, they show that there were in fact four warm-spells; three of them combined with precipitation in the period from February 26th to March 21 st, 2011, that explain the anomaly.

The last warm-spell was followed by nearly two weeks of cold weather lasting to April 1st, i.e., 8 days before artificial thawing was about to start. As refreezing occurs with a time lag increasing with depth and typically at a lower rate in soils with a high 
proportion of water-susceptible fines, the tail end of the thaw-freeze cycle would still be noticeable the way it appears at 0.5-0.9 m depth in Fig. 9(b).

Now, focusing at the soil near the ground surface at $0.1 \mathrm{~m}$ depth in particular (Figs. 8 and 9), both the sharp increase to begin with and the generally high temperature as the thawing progresses are as expected, considering the proximity to the heat source. Referring to 2012 (Fig. 8), a snapshot $24 \mathrm{~h}$ into the experiment reveals that gravelly sand has reached $29^{\circ} \mathrm{C}$, silty sand $23^{\circ} \mathrm{C}$ and uniform gravel $18^{\circ} \mathrm{C}$. The same for 2011 (Fig. 9) yields 35,37 and $21^{\circ} \mathrm{C}$, respectively. In general, the temperatures obtained in 2011 are slightly higher compared with those in 2012 . The $37^{\circ} \mathrm{C}$ in silty sand from 2011 seems anomalous compared with gravelly sand. This is reasonable if the silty sand at that depth was already thawed when the experiment started, because the soil temperature would rise from the beginning and from an initial value above $0^{\circ} \mathrm{C}$, instead lingering near $0^{\circ} \mathrm{C}$ during the phase change before starting to climb.

The uppermost soil temperature sensors $(0 \mathrm{~m})$ are actually placed $1-2 \mathrm{~cm}$ below ground surface level. Looking one week into the experiments, the temperatures have risen to approximately $74-75^{\circ} \mathrm{C}$ in gravelly sand, $\sim 65-70^{\circ} \mathrm{C}$ in silty sand and $\sim 66-69^{\circ} \mathrm{C}$ in gravel. Some variations are expected, especially when considering the integrity of the thin soil layer covering the sensors and the varying positioning of the pipes from one experiment to the next. As previously shown (Fig. 1), even when using horizontal spacers, there were some variation in distance between the pipes from one experiment to the next.

On the opposite end, comparing the temperature trends at 1.5-1.8 m depth in silty sand from both experiments, the thermal responses appear to be occurring nearly at the same time. This phenomenon is typical for situations when the thaw front has penetrated the frozen layer and excess water starts draining out. As gravity and capillary forces now govern downwards water migration, it occurs at a faster pace compared with the slow rate of thawing, resulting in the thermal responses appearing closer to each other on the time axis.

\section{Thaw Rates-Thaw Depth versus Time}

One way of evaluating the performance characteristics of the hydronic method is quantifying the rate at which it is able to thaw various types of soils. In this study, the thaw rates are given by calculating the time it takes from initial thawing to when there is a definite thermal response on the time axis. Close-ups of the soil temperatures near zero degrees are evaluated individually for each depth and soil type. During the phase change, the temperatures rest at approximately $0^{\circ} \mathrm{C}$, also known as the zero curtain effect (Hinkel and Outcalt 1995). The latent heat absorption reduces or halts the warming effect until all the ice in the soil at the particular depth has thawed. When the phase transition is complete, the soil temperatures start rising. The time at which this occurs, relative to the start of the artificial thawing process, is determined for all sensor 


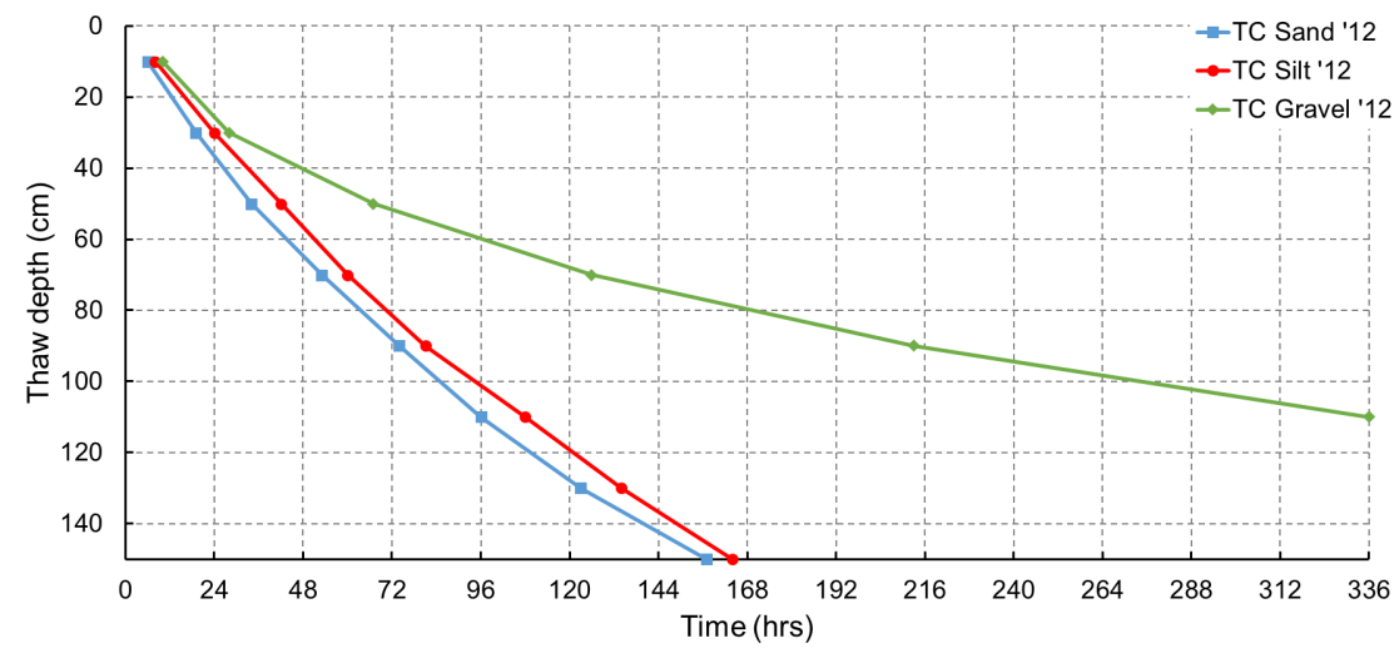

a)

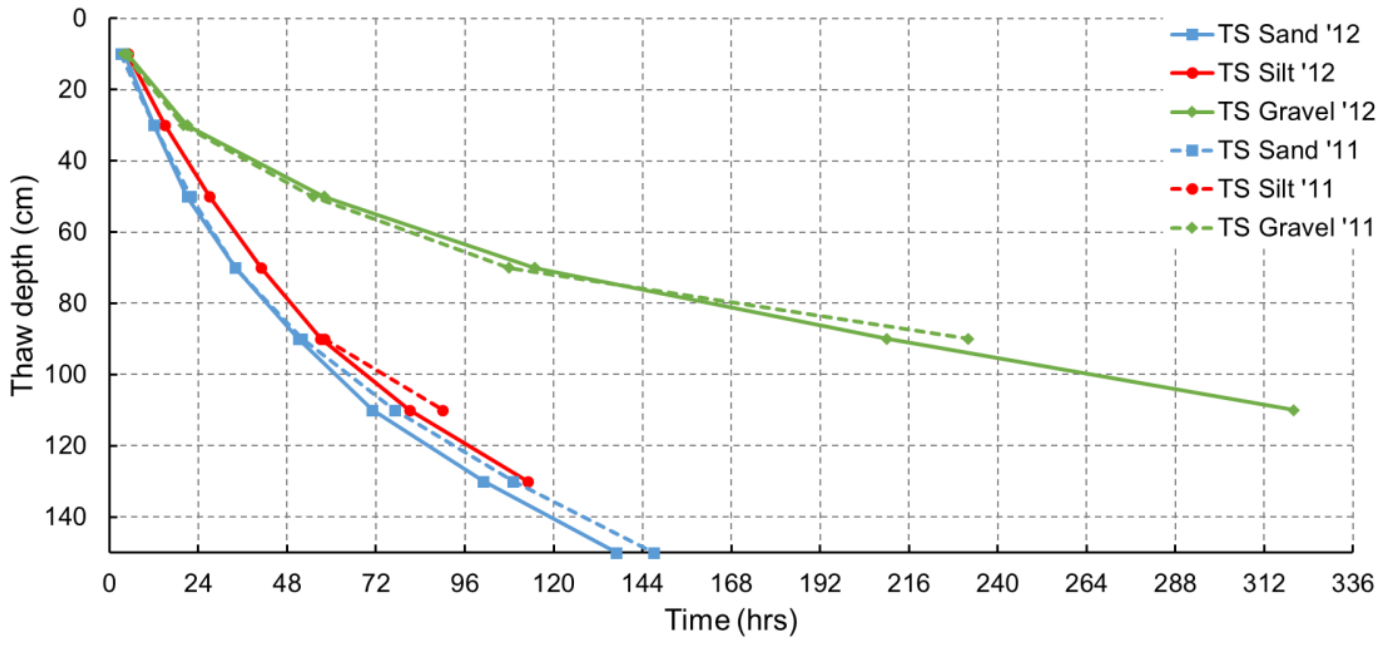

Fig. 10. Thaw rates based on; (a) thermocouple (TC) records from 2012; (b) thermistor string (TS) records from both 2012 and 2011

depths. Put together for a particular type of soil, this expresses the thaw rate.

In this study, two sets of soil temperature records are available; one based on smallsized thermocouples in direct contact with the soil, as shown in Figs. 8 and 9, and the other on thermistor strings inside air-filled, sealed tubes embedded in the soil. The resulting thaw rates from both types of sensors are shown in Fig. 10. The records shown in Fig. 10(b) cover both experiments (2012 and 2011) and all soils, but only the likely frozen region with respect to silty sand in 2011 (0.9-1.1 m depth).

According to the thaw rates compiled from the thermocouple records from 2012 shown in Fig. 10(a), the hydronic method performs slightly better in gravelly sand compared with silty sand, and considerably better compared with uniform gravel. The time needed for the thaw to penetrate to $1 \mathrm{~m}$ depth $(100 \mathrm{~cm})$ is $85 \mathrm{~h}(\sim 3.5$ days $)$ in sand, $94.5 \mathrm{~h}(\sim 4$ days $)$ in silty sand and $274.5 \mathrm{~h}(\sim 11.5$ days $)$ in gravel. Similar for the tubed thermistor strings shown in Fig. 10(b), are $61 \mathrm{~h}$ ( $\sim 2.5$ days $)$ in sand, $69 \mathrm{~h}$ ( $\sim 2.9$ days $)$ in silty sand and $265 \mathrm{~h}$ ( $\sim 11$ days) in gravel. The resulting thaw rates from the 2012 experiment based 


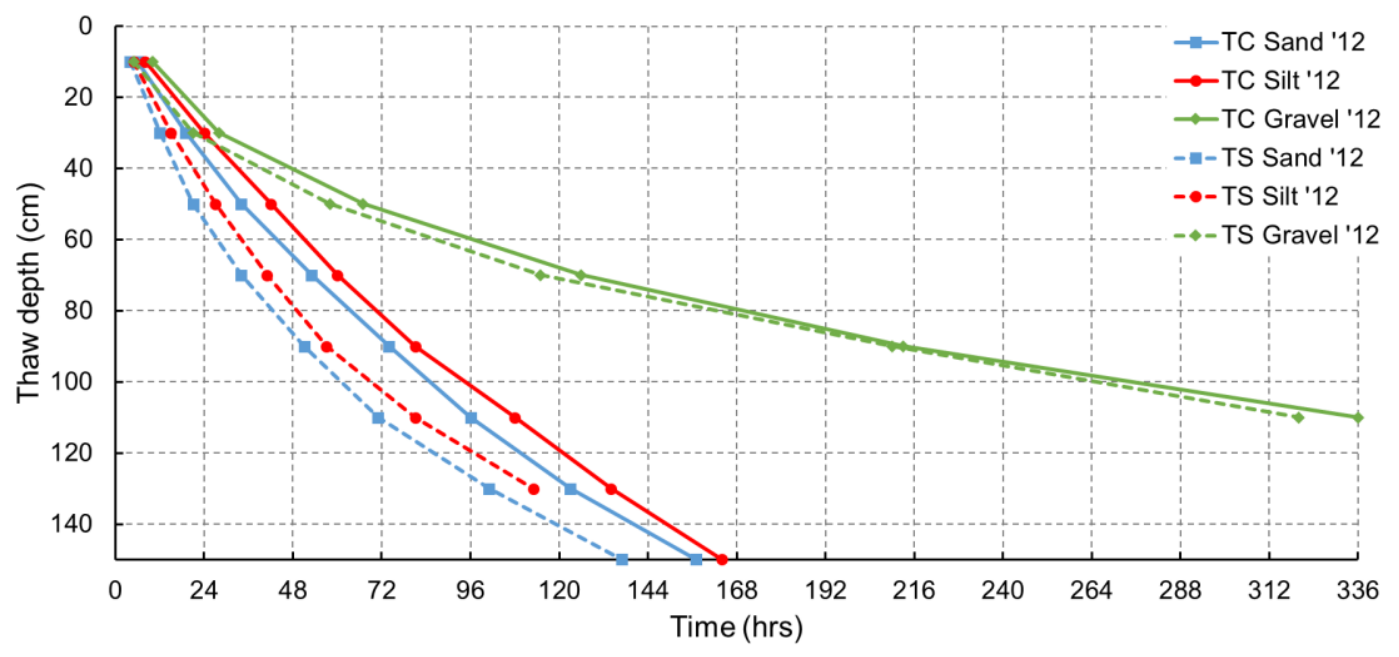

Fig. 11. Comparing thaw rates based on thermocouple (TC) and thermistor string (TS) records from 2012

on each of the two methods are combined and compared in Fig. 11. The differences are considerable, especially when comparing gravelly and silty sand. According to the thermistor string records it takes one day less for the thaw to penetrate $1 \mathrm{~m}$ compared with the thermocouple records. For uniform gravel, the difference is approximately 0.5 days at the same depth. This suggests that the measurement principle, type and the physical dimension of the sensors must be taken into consideration when determining thaw rates.

An earlier study by Miller (Esch 2004) showed excellent conformity between direct and indirect soil temperature measurements, even without an insulating annulus between the sensors inside the tube. Measured temperatures in a variety of fluid-filled tubes showed marginal convective turnover and no noticeable error. In one extreme case, thermistors were placed inside an air-filled, $45.7 \mathrm{~cm}$ diameter, closed steel pipe and compared with temperatures taken in the adjacent soil, $4.57 \mathrm{~m}$ outside the pipe. The temperature difference between the air inside the pipe and the adjacent soil at the same depths was within $0.4^{\circ} \mathrm{C}$ over 7 months of monitoring. The disparities were seen during the period of phase change.

Comparing the sensor dimensions and the temperature trends for both sensor types in this study, it appears that the relatively large thermistors (height $50 \mathrm{~mm}$ ) are affected by the thaw front moving downwards well before the small-sized thermocouples (height 6 $\mathrm{mm}$ ). Tubed thermistor strings are hence overestimating the thaw rates, at least for saturated soils and shallow depths. The differences appear to diminish with depth, suggesting that the discrepancies might be smaller or absent for depths beyond $\sim 2 \mathrm{~m}$. This may be of general interest and possibly have implications when interpreting data for ongoing and future monitoring at permafrost sites, where drilled holes and tubed thermistor strings are commonly used (Harris et al. 2009; Isaksen et al. 2007; Haeberli et al. 2006). 
Table 2. Thaw Depth versus Time Listings for Artificial Thawing Methods Used on Gravelly Sand (SP), Clayey Gravels (GC) and Sandy Gravel (GW)

\begin{tabular}{|c|c|c|c|c|c|c|}
\hline \multirow[b]{2}{*}{ Reference } & \multirow{2}{*}{$\begin{array}{l}\text { Thawing } \\
\text { method }\end{array}$} & \multirow{2}{*}{$\begin{array}{l}\text { Unified soil } \\
\text { classification }\end{array}$} & \multicolumn{4}{|c|}{ Time (h) to thaw } \\
\hline & & & $0.2 \mathrm{~m}$ & $0.3 \mathrm{~m}$ & $0.5 \mathrm{~m}$ & $1.0 \mathrm{~m}$ \\
\hline Present study & Hydronic & SP & 13 & 19 & 34 & 85 \\
\hline $\begin{array}{l}\text { Sveen and Soeren- } \\
\text { sen (2010) }\end{array}$ & Hydronic $^{\mathrm{a}}$ & SP & 12 & 18 & 35 & 137 \\
\hline $\begin{array}{l}\text { Hermansson and } \\
\text { Guthrie (2006) }\end{array}$ & Infrared & $\mathrm{GC}$ & 34 & $>57$ & - & - \\
\hline \multirow{3}{*}{$\begin{array}{l}\text { Oswell and Graham } \\
\text { (1987) }\end{array}$} & Propane $^{\mathrm{b}}$ & \multirow{3}{*}{$\mathrm{GW}^{\mathrm{e}}$} & - & 9 & 16 & 37 \\
\hline & $\mathrm{Coal} / \mathrm{straw}^{\mathrm{c}}$ & & - & 10 & 19 & 45 \\
\hline & Electric $^{\mathrm{d}}$ & & - & 41 & 52 & 81 \\
\hline
\end{tabular}

Note: Hermansson and Guthrie (2006) do not contain information about thaw depth versus time at 0.5 and $1.0 \mathrm{~m}$ depth; the same applies for Oswell and Graham (1987) at $0.2 \mathrm{~m}$ depth. ${ }^{a} 70 \mathrm{~kW}$ gross burner capacity as opposed to $103 \mathrm{~kW}$ used in the present study.

${ }^{b}$ System of four steel pipes set in a $0.3 \mathrm{~m}$ thick blanket of sand through which hot air from propane burners located at one end passed.

${ }^{\mathrm{c}}$ Coal placed on a straw bed and burned directly on the ground surface.

${ }^{\mathrm{d}}$ System of three $240 \mathrm{~V}$ radiant heaters placed below a reflective cover on the frozen surface.

${ }^{\mathrm{e} A c t u a l}$ soil classification not listed in reference, described as sandy gravel.

Table 2 contains a list of artificial thawing methods referred to in the "Introduction", except for microwave (Lindroth et al. 1995), with accompanying thaw rates for various soils. The table also includes the hydronic method utilized on gravelly sand from the present paper, and the initial study by the authors from 2007 (published in 2010).

Caution must be taken when comparing the various methods presented in Table 2. To begin with, the type, composition and initial conditions of the soils vary. Furthermore, there are differences in the experimental setups and methodologies used. For example, the steel pipes utilized for propane heating were covered with $30 \mathrm{~cm}$ of sand. In comparison, the other methods apply the heat load onto or at some distance from the frozen ground surface.

With that in mind, a closer examination of the various methods and the achieved thaw rates listed reveals some interesting points. Starting with the hydronic method, the results from 2012 compares well with those from 2007. The exception is the comparatively shorter time needed to thaw $1 \mathrm{~m}$ of frozen ground in 2012. Considering that the gross effect of the oil burner used in 2012 was $103 \mathrm{~kW}$ as opposed to $70 \mathrm{~kW}$ in the 2007 experiment; this is reasonable because the applied heat load is nominally 47 $\%$ larger. These results compare directly, because both the methodology and experimental setups are similar, and with analogous initial conditions. Infrared heating, on the other hand, was used to thaw clayey gravels with comparatively higher initial water (and ice) content. Furthermore, the heat was applied as radiation from a $22 \mathrm{~kW}$ infrared heater suspended approximately $2.4 \mathrm{~m}$ above the ground. Considering that the soil temperature at $0.3 \mathrm{~m}$ depth had not risen above zero after $57 \mathrm{~h}$ of continuous 
operation, the method seems applicable for relatively shallow frost depths. Applied on dryer soil, the method could possibly extend the thaw depth.

In the case of artificial thawing utilizing propane, coal, and electrical (radiant) heat performed by Oswell and Graham (1987), the field test program, scope of the investigation and soil types resemble the present study. Unfortunately, the authors did not disclose details about the soils used other than characterizing them as sandy gravel and clay till. However, from the achieved thaw rates it is likely that the initial water and ice content was comparatively low and that the sandy gravel was well-graded with little or no fines. Both propane and coal heating show very rapid thawing. Considering the high surface temperatures reported, ranging from approximately $300-400^{\circ} \mathrm{C}$ for propane and up to $550^{\circ} \mathrm{C}$ for coal; this is reasonable. In addition, electrical (radiant) heating performs well, although the heat load reportedly was erratic and unevenly distributed. This is obvious when looking closer at the time needed to thaw $0.3,0.5$ and $1.0 \mathrm{~m}$, which shows a linear trend instead of the expected logarithmic trend.

\section{Applicability and Costs Involved}

It is noteworthy that except for hydronic heating, the authors have not found any sources referring to the methods listed in Table 2, including microwave heating, being commonly used today. It suggests these methods have not seen further development or use outside the referenced experiments. This, and because operating costs are not a subject in the relevant papers, makes it difficult to compare the methods in terms of costs. By contrast, hydronic heating has proven its efficiency within artificial thawing of frozen ground since the introduction to the U.S. and Canadian markets 20 years ago (Stewart 1996). Additionally, the defrosting system referred to in this study has seen extensive use in Scandinavia and Russia over the last decade (Johansen 2013). According to the manufacturer, close to one thousand units have been sold to the European and Russian markets since the introduction in 2005. Their product range now covers applications as diverse as air and water heating, concrete curing and pest control (Heatwork AS 2016).

Although a proper economic analysis comparing the various methods is not feasible, and besides outside the scope of this paper, Fig. 3 gives an idea of the costs involved with regards to hydronic heating in particular. It shows the actual and accumulated fuel consumption during the experiment in March 2012. All three hot-water pipes were in use, covering an area of approximately $60 \mathrm{~m}^{2}$ in total $(4.5 \mathrm{x} 4.5 \mathrm{~m}$ per bin, referring to Fig. 5). As shown, the fuel consumption per $\mathrm{h}$ is high to begin with, becoming gradually lower over time. In this case, the average fuel consumption during the initial 24-h period was $5.0 \mathrm{~L} / \mathrm{h}$. Similar fuel consumption after one and two weeks of thawing was 3.0 and $2.7 \mathrm{~L} / \mathrm{h}$, respectively. Note that even though this refers to the particular experiments and defroster model (HW 3600) used in this study, the general trend is the same for normal thawing operations. Utilized on shallow frost depths and consequently over short time periods, the average fuel consumption per $\mathrm{h}$ is higher relative to large frost depths and 
long time periods. To end users however, the total or accumulated consumption is typically more important, which in this case was $119 \mathrm{~L}$ after $24 \mathrm{~h}, 504.5 \mathrm{~L}$ after one week and 894.4 L after two weeks of continuous thawing.

In terms of manpower, the equipment is operated by one person, which after $2-4 \mathrm{~h}$ of initial preparations leaves the defroster running on its own. The system will then generate a standard text message by the GSM-network whenever fuel replenishing is needed, typically approximately every $48 \mathrm{~h}$ during normal thawing operations, or if an error occurs. When the required thaw depth is reached, the operator will spend approximately the same amount of time finalizing the operation as when preparing it.

\section{Conclusion}

The evaluation of the performance characteristics of the hydronic thawing method is based on soil temperature records from full-scale thawing experiments on three types of soils, carried out during the winters of 2011 and 2012. The resulting thaw rates are compared internally, to an initial experiment by the authors performed in 2007 and to related research work on artificial thawing. As the authors have demonstrated in an earlier paper (Sveen and Soerensen 2013), a number of considerations were made during the planning and establishment of the laboratory to ensure comparable results from one season to another. This applies to the preparations prior to and during fieldwork.

1. Hydronic heating is demonstrably an effective method for artificial thawing of frozen ground. Because it utilizes conduction as the main heat transfer mechanism, the thaw efficiency is especially good in low porosity soils with little or no fines such as gravelly sand.

2. The thaw efficiency declines with increasing fines content (frost susceptibility) and void ratio (porosity). With moderate, initial water content, the method is capable of thawing $1 \mathrm{~m}$ in $85 \mathrm{~h}$ ( $\sim 3.5$ days) in gravelly sand, $94.5 \mathrm{~h}$ ( $\sim 4$ days) in silty sand and $274.5 \mathrm{~h}$ ( $\sim 11.5$ days) in uniform, crushed gravel.

3 . The thaw rates generally decrease with increasing depth or distance to the heat source, varying from $22-37 \mathrm{~cm} /$ day after one day of operation to $12-24 \mathrm{~cm} /$ day after six days of operation. A diminishing (transient) heat load with time is a contributing factor.

4. The effect of increasing the oil burner capacity and thus higher supply temperatures is more evident the longer the thawing process is running, i.e., primarily noticeable below $0.5 \mathrm{~m}$ depth in gravelly and silty sand.

5. The soil temperatures are principally responding to the applied heat load rather than variations in ambient air temperature, attributable to comparatively high supply temperatures and the use of insulation covers. Ambient air temperature variations in the range of -7 to $8^{\circ} \mathrm{C}$ had no noticeable effect on the soil temperatures from $0.1 \mathrm{~m}$ depth and downwards during thawing. 
6. The measurement principle, type and physical dimension of the soil temperature sensors must be considered when determining thaw rates. Compared with thermocouples embedded in the soil, tubed thermistor strings overestimate the thaw rates for saturated soils and at shallow depths. The differences diminish with depth, suggesting that the discrepancies might be smaller or absent for depths beyond $\sim 2$ m.

Finally, it is noteworthy that the results in this study are compiled from a small number of experiments, and consequently provide more of a circumstantial rather than a generic characterization of the performance rate of the hydronic method. Additional experiments are recommended to evaluate the thaw efficiency for a wider range of initial soil conditions.

\section{Acknowledgments}

This study is funded by Nordland County council, the ColdTech project (RT4-01) and Heatwork AS. The authors are grateful for the support in establishing the Frost in Ground laboratory (FiG-lab) and the access to the facilities during this work. The authors also thank Heatwork AS for providing the defrosting system used during the experiments.

\section{References}

Andersland, O. B., and Ladanyi, B. (2004). Frozen ground engineering, 2nd Ed., Wiley, NJ.

Bansal, N. K., and Shail (1999). "Characteristic parameters of a hypocaust construction." Build. Environ., 34(3), 305-318.

Beistline, E. H. (1963). "Placer mining in frozen ground." Proc., Int. Conf. on Permafrost, National Academy of Sciences-National Research Council, Washington, DC, 463-467.

Cengel, Y. A. (2002). Introduction to thermodynamics and heat transfer, Int. Ed., McGraw-Hill, Singapore.

Esch, David C. (2004). "Thermal analysis, construction, and monitoring methods for frozen ground.", Chapter 3, Temperature monitoring/ground thermometry, Duane Miller, Reston, VA, 57-75.

Freitag, D. R., and McFadden, T. T. (1997). Introduction to cold regions engineering, ASCE Press, Reston, Va.

Haeberli, W., et al. (2006). "Permafrost creep and rock glacier dynamics." Permafrost Periglacial Processes, 17(3), 189-214. 
Harris, C., et al. (2009). "Permafrost and climate in Europe: Monitoring and modelling thermal, geomorphological and geotechnical responses." Earth-Sci. Rev., 92(3-4), 117171.

Heatwork AS. (2016). "Areas of application." 〈http://heatwork.com/en/areas-ofapplication/> (Jun. 24, 2016).

Hermansson, A., and Guthrie, W. S. (2006). "Numerical modeling of thaw penetration in Frozen ground subject to low-intensity infrared heating." J. Cold Reg. Eng., 10.1061/(ASCE)0887-381X(2006)20:1(4), 4-19.

Hinkel, K M., and Outcalt, S. I. (1995). "Detection of heat-mass transfer regime transitions in the active layer using fractal geometric parameters." J. Cold Reg. Sci. Technol., 23(4), 293-304.

Isaksen, K., Sollid, L., Holmlund, P., and Harris, C. (2007). "Recent warming of mountain permafrost in Svalbard and Scandinavia." J Geophys. Res., 112(F2), F02S04.

Johansen, G. (2013). "Success with mobile heating." Anleggsmaskinen (in Norwegian), 53(4), 52-54.

Jumikis, A. R. (1979) "Some aspects of artificial thawing of frozen soils." Eng. Geol., 13(1-4), 287-297.

Lindroth, D. P., Berglund, W. R., and Wingquist, C. F. (1995). "Microwave thawing of frozen soils and gravels." J. Cold Reg. Eng., 10.1061/(ASCE)0887-381X(1995)9:2(53), $53-63$.

Oswell, J. M., and Graham, M. D. (1987). "Thawing frozen ground: field trials and analysis.” J. Cold Reg. Eng., 10.1061/(ASCE)0887-381X(1987)1:2(76), 76-88.

Stewart, L. (1996). "Heaters thaw frost fast." 〈https://www.highbeam.com/doc/1G118648185.html〉 (Dec. 17, 2015).

Sveen, S. E., and Soerensen, B. R. (2010). "Effective thawing of frozen groundPerformance testing of a new thawing method based on hydronic heat." Proc., 3rd European Conf. on Permafrost (EUCOPIII), Univ. Centre in Svalbard, Svalbard, Norway.

Sveen, S. E., and Soerensen, B. R. (2013). "Establishment and instrumentation of a full scale laboratory for thermal and hygroscopic investigations of soil behavior in cold climates." J Appl. Mech. Mater., 239, 827-835.

TSI (2004). "Combustion analysis: An overview of measurements, methods and calculations used in combustion analysis." 〈http://www.tsi.com/uploadedFiles/_Site_Root/Products/Litterature/Handbooks/CAbasic-2980175.pdf> (Dec. 17, 2015). 